\title{
IMPROVEMENT OF THE BEARING CAPACITY OF CONFINED AND UNCONFINED CEMENT- STABILIZED AEOLIAN SAND
}

\author{
Susana Lopez-Querol' ${ }^{1}$ Juana Arias-Trujillo2,+, Maria GM-Elipe ${ }^{3}$, Agustin Matias-Sanchez ${ }^{2, *}$, \\ Blas Cantero ${ }^{2, * *}$ \\ 1: Author for correspondence, Department of Civil, Environmental and Geomatic Engineering, \\ University College London (UCL), London WC1E 6BT (UK). Tel. N. +44 (0)20 7679 2722, Email \\ address: $\underline{\text { s.lopez-querol@ul.ac.uk }}$
}

2: School of Engineering, Department of Construction, University of Extremadura, Avda. de la Universidad, s/n, 10003, Caceres (Spain), Email addresses: +: jariastr@unex.es; *: amatias@unex.es;

**: bcantero@alumnos.unex.es

3: School of Civil Engineering, University of Castilla - La Mancha. Avda. Camilo Jose Cela s/n, 13071 - Ciudad Real (Spain). Email address: maria.gme@outlook.com

\section{Abstract}

The improvement reached on the compaction and bearing capacity of aeolian sand collected in Jeddah (Saudi Arabia) after its stabilization with Portland cement is evaluated, comparing the behavior for both treated and untreated samples. With the aim of using this type of soil in the construction of embankments for road or railway applications, the results obtained have been evaluated in terms of maximum dry density, optimum moisture content (compaction test) and bearing capacity (CBR). Special attention has been paid to the influence of the confining conditions on the results, scarcely analyzed in the literature, by comparing the load-displacement curves during penetration stage in the CBR tests for both confined and unconfined specimens. Different contents of Portland cement have been explored (out of $6 \%$ of dry soil weight) to stabilize this material. The results obtained show a clear linear correlation between of compaction characteristics and CBR respect to the percentage of cement, obtaining, as expected, higher improvement for treated-material with higher content of cement, also strongly influenced by the confinement state. Thanks to this treatment, it is possible to employ this material in applications with low-confinement support, which is impossible without a previous proper stabilization. Finally, two practical indices have been defined to measure the degree of improvement reached, involving both cement content and confinement.

Keywords: Aeolian sand; Portland cement stabilization; Compaction; Bearing capacity; Confined and Unconfined Conditions; Ground improvement 


\section{Introduction}

From the construction application point of view, aeolian sands are very particular materials due to their poor grading because of their very uniform particle size distribution, fine mean size and rounded shape of their particles. In general, these soils are suitable for construction purposes, as they are granular materials with low fines content, and even without plasticity, and with a relative high permeability which makes them to perform properly in contact with water. However, several difficulties arising during the construction determines their utilization, mainly under compaction process, particularly for low-confinement geotechnical structures like in the lateral sides of embankments. Because of that, this material is usually substituted by alternative soils when available nearby the construction site. However, in so many areas in the world, especially in extensive arid locations, aeolian sands are the only available materials, and therefore it is absolutely necessary to improve their workability conditions and to overcome their drawbacks to make them suitable as well as to ensure the engineering requirements.

Along the $19^{\text {th }}$ and $20^{\text {th }}$ centuries, so many relevant researches were published focused on the origin and characterization of aeolian sand [1], particular cases studies [2,3] and paying special attention to the geological aspects [1], as well as to geomorphology and sedimentology properties [4-10]. Respect to the characterization of aeolian sands, recent studies mainly exploring their mineralogical composition and textural features can be found in the literature [11-13].

The first attempts to evaluate the suitability of this soil as construction material was published by Khan (1982) [14], based on the analysis of several samples from Libya, where relevant implications of its utilization in highways are discussed, whereas Al-Sanad and Bindra (1984) [15] analyzed different samples collected from dune sands in Saudi Arabia. After those preliminary investigations, the early systematic geotechnical characterizations of aeolian sands, supported by laboratory-tests, were published in [16-25], concluding with guidelines for its application for construction purposes. A comprehensive review of the most common geotechnical properties of aeolian sands in the world, extracted from a huge collection of bibliographic sources, can be found in Elipe and Lopez-Querol [26].

As brief, the most representative geotechnical characterization and properties of aeolian sand can be summarized as follows: uniform material, with particle sizes usually ranging from $0.08 \mathrm{~mm}$ to $0.40 \mathrm{~mm}$. The particles are also very rounded (i.e. small spheres) with a main chemical 
composition of silica. The specific gravity, which is obviously related to the mineralogy of the particles, ranges from 2.4, in Egypt dunes, to 2.87, in India dunes. The differences between minimum and maximum dry densities are small, the later ranging from $1640 \mathrm{~kg} / \mathrm{m}^{3}$ to $1765 \mathrm{~kg} / \mathrm{m}^{3}$, while the optimum moisture content varies between 11 to $14.5 \%$. The compaction curves exhibit a very flat shape without a clear maximum value, and therefore a maximum density cannot be clearly established. Unlike common soils, aeolian sands usually present a minimum dry density for low water contents, at around $2 \%-4 \%$. The cohesion is negligible for these soils, while the friction angle is very significant, varying between $39^{\circ}$ to $42^{\circ}$. The permeability of this material is quite high, typical for sands with small fines content, ranging between $10^{-2} \mathrm{~m} / \mathrm{s}$ and $10^{-4} \mathrm{~m} / \mathrm{s}$. In general, these soils are classified as SP or SP-SM according to USCS classification system, or as A-1, A-3 or A2 according to AASHTO. Both classifications identify these soils as suitable for embankment construction purposes, and also The World Road Association (PIARC) prescribes their suitability for construction if they are conveniently treated [27].

A wide collection of different treatments and techniques of stabilization have been tried and reported in the literature over the last decades although, nowadays neither of them has been considered as a predominant procedure for the stabilization of aeolian sands. The options of improvement of the geotechnical behavior of these soils, avoiding substitution, vary from compaction to admixture with different additives, like cement, bitumen emulsions, chemical emulsions, reinforcement materials, wastes, ceramic tiles, etc. [26], and also with different combinations of two of them trying to enhance their individual benefits. Among them, Portland cement has been the most employed additive for the improvement of aeolian sand [28-32], although traditionally the use of cement in soil stabilization is well-established for many other types of soils.

Regarding the cement-stabilization for aeolian sand, the dosages reported by different researchers are significantly high, ranging from $8 \%$ until $20 \%$, which in general is far from practical and economic considerations. Thanks to that, excellent results in terms of higher strength and bearing capacity have been obtained in the testing specimens. However, scarce attention has been devoted so far to the improvement and analysis of the material behavior under low confinement conditions, in spite of its well-recognized poor performance under such conditions, including the difficulty in its compaction during the construction of embankments. To fill this gap in the treatment of aeolian sand, particularly for cement stabilization, a novel variation of the California Bearing Ratio 
(CBR) has been employed in this research to take into account the confinement of the testing specimen. Moreover, a tool to evaluate the improvement reached by means of the treatment, under high or low confinement conditions, is provided.

Whereas Proctor and CBR tests are the reference laboratory experiments employed in road engineering in the practice, they are almost omitted in the literature related to stabilization of aeolian sands [26] and usually substituted by UCS (Unconfined Compressive Strength) which cannot be employed directly for bearing capacity analyses. Because of that, and thanks to the relative low dosage of cement adopted in this research, Proctor and CBR have been maintained as reference experiments.

In this paper, an experimental research has been developed to analyze the influence on compaction and bearing capacity response of aeolian sand stabilized with three different contents of Portland-cement, equal to $2 \%, 4 \%$ and $6 \%$ of dry weight of soil, as ground improvement technique, paying special attention to the influence of confinement condition. The sand employed in this research was collected in Jeddad (Saudi Arabia), 78km far from La Meca, and very close to the new high speed train line from Medina to La Meca.

First, a detailed description of the Jeddah aeolian sand is presented, including a Laser-ray diffraction, a mineralogical analysis by means of X-ray diffraction (XRD) and a morphologic analysis with electronic microscope (SEM), apart from sieving analyses. After that, the samples preparation and testing procedures following along the experimental work are described. The effects of the treatment on the compaction properties and bearing capacity, which is the main objective of this research, have been investigated by means of variations of the conventional Modified Proctor tests and CBR test, respectively. Finally, the main results obtained from these tests are presented. The influence of the confinement degree on the tested specimen in terms of bearing capacities is explored and discussed, since as it has been exposed previously, it has been identified as the main drawback of this material in the construction of different types of geotechnical structures such as embankments. Two new indices to evaluate the effectiveness of the treatment on bearing capacity of aeolian sands are proposed as a very simple but efficient and practical procedure to evaluate the degree of improvement reached for this type of soil. At the end of the paper, the most relevant conclusions are highlighted. 
The materials used in this research are aeolian sand from Jeddah (Arabia Saudi), cement (as additive) and water. The cement employed is a high initial strength Portland cement class I with strength of $42.5 \mathrm{MPa}$ [33]. For the Jeddah aeolian sand, the necessary laboratory tests were conducted to determine its physical and engineering properties. A detailed characterization is included next.

a) Sieving analysis

The particle size distribution analysis by sieving [34] demonstrates that the vast majority of particles are ranging from $0.08 \mathrm{~mm}$ and $0.63 \mathrm{~mm}$, Figure 1 , with a fines content equal to $1.38 \%$. This sand does not exhibit plasticity but displays positive qualitative carbonate content. The characteristics of this sand are listed in Table 1. According to the USCS classification system [35], this sand is classified as SP (poorly graded sand) and according to AASHTO system [36] it is A3.

b) Laser-ray diffraction analysis For clarifying, Figure 2 presents a picture of the different sizes of the aeolian sand.

A Laser-ray diffraction analysis was carried out on the material, without using ultrasounds in the equipment to prevent the destruction of the finest particles. Figure 3 shows the particle size distribution analyses. Sieving and laser-ray diffraction procedures yield very similar results.

\section{7}

c) Mineralogical analysis

A mineralogical analysis was also undertaken by means of X-ray diffraction (XRD). This study determines the mineral composition of this sand, which is listed in Table 2. As expected, quartz is the predominant mineral in this sand. The small amount of feldspar explains the reddish color of this sand, due to its oxidation [37].

\section{d) Morphologic analysis}

Finally, a morphologic analysis was carried out with an electronic microscope (SEM), with resolution ranging from $3 \mathrm{~nm}$ to $10 \mathrm{~nm}$. A representative sand sample was sieved and separated into two fractions: a fraction with particle sizes higher than $0.160 \mathrm{~mm}$, labelled as $\mathrm{Y}-1 \mathrm{G}$, and the finest part (particle size smaller than $0.160 \mathrm{~mm}$ ) identified as $\mathrm{Y}-1 \mathrm{~F}$. The sub-Figure $4 \mathrm{a}$ and $4 \mathrm{~b}$ show 

shapes of the particles can be clearly observed. Because of the wind erosion, it is possible to identify surface textures in some particles.

The sample $\mathrm{Y}-1 \mathrm{G}$ is homogeneous in the shape of its particles which are rounded without sharp edges, as consequence of the high energy level suffered during its transportation process. This characteristic can be observed in detail in Figure 5, where sub-figures $5 a$ and $5 b$ correspond to x400 and x800 micrographs for the same fraction, respectively. These photographs demonstrate that the microstructure of these particles, with sizes ranging from $0.29 \mathrm{~mm}$ to $0.767 \mathrm{~mm}$, is clean. Furthermore from Figure 5c (out of x3000 micrographs), in some particles it can be observed a posterior filling deposited in some cavities.

In contrast, the finer fraction of the sand $(\mathrm{Y}-1 \mathrm{~F})$ presents higher heterogeneity. In general, these particles are less rounded, displaying grooves, edges, slabs and fractures caused, at least, by two different transportation processes, one of them causing the grooves (Figure 6a and Figure 6b) and the other one producing the fractures (Figure 6c).

\section{Testing procedures}

As previously mentioned, the objective of this research is to characterize and investigate the effects of cement stabilization on the compaction and bearing capacity of the Jeddah aeolian sand, with special attention to the degree of confinement in the specimen. This experimental research was carried out in the Geotechnical Laboratory at the University of Extremadura (Caceres, Spain).

Three different contents of cement have been investigated, namely $2 \%, 4 \%$ and $6 \%$, respect to dry weight of the soil. The properties investigated are: moisture content-dry density relationship and bearing capacity with lateral confinement and without it, by means of a variation of the conventional compaction test (Modified Proctor) and CBR, which are detailed next. For comparison purposes, untreated specimens were also tested both with compaction test and bearing capacity test, in order to evaluate the improvement reached by means of the cement-stabilization.

\subsection{Compaction test}

First, compaction tests were carried out aiming at obtain the relationship between maximum dry density and optimal water contents for each case. These tests were developed for both untreated sand and for sand improved with the different percentages of cement, in particular to 
evaluate the effect of the additive on the compaction performance of the mixture. Two complete compaction curves were carried out for each cement content, to check repetitiveness and consistency of the achieved results, and the average value was adopted. In each curve, at least five points or more have been considered with a proper distribution of them between the dry and wet part of the compaction curve.

For the compaction process, a modification of the Modified Proctor procedure [38] has been adopted to simplify the laboratory operability and to prepare the samples according to the modified CBR tests under optimal conditions, as explained later. In particular, the tested specimens were elaborated with a reduced height, respect to the conventional test, and consequently the number of layers necessary was also recalculated in order to guarantee that both procedures were equivalent in terms of compaction energy by unitary volume. The dimensions of the tested specimens and the compaction particularities are included in Table 3. For all experimental works, the compaction was applied by means of an automatic compactor.

\subsection{Bearing Capacity test}

The main drawback of using aeolian sands in construction of embankments occurs when the material is under low confinement conditions, i.e. at the lateral sides. In order to investigate this problem in the laboratory, a modification of the conventional CBR testing has been developed, aiming to highlight, at first, the improvement reached by means of the admixture of cement as stabilizer, respect to the untreated sand, and at second, to capture the properties of the improved material for low-confinement conditions respect to the confined situation. For determining the bearing capacity, a modification of the CBR test [39] has been employed.

The dimensions of each CBR specimen is maintained equal to the compaction case, also using three layers (Table 3). For a CBR test, a total of three specimens are necessary since the number of blows by layer changes from 15,30 to 60 , which represents a fraction equal to $25 \%, 50 \%$ and $100 \%$ of the Modified Compaction Energy [39]. For each percentage of cement and for each confinement conditions, two complete "modified" CBR tests were developed.

In each case (untreated sand or each content of cement) and for the corresponding compaction energy, the samples were prepared by mixing aeolian sand, the corresponding content of cement (respect to the dry weight of soil) and the water necessary to reach the optimum moisture content determined from the previous corresponding compaction test. Moreover, extra water content, equal 
to $2 \%$ of weight of cement content, was added as consequence of the hydration process of the cement. No immersion stage was considered due to the lack of plasticity of the sand.

When each specimen was elaborated, it was cured in a concrete curing room at an average temperature of $(20 \pm 2)^{\circ} \mathrm{C}$ and average relative humidity equal or higher than $95 \%$ [40]. The specimens designated to the confinement-test were kept into their molds along the whole curing process, however those specimens reserved for the unconfinement-test were cured outside of their molds. The specimens were tested after 7 days of curing, which is a period of time usually considered in soil cement-stabilization. After that, the samples were tested in a multi-function load frame to determinate the "modified" CBR ratio, where an uniform overload of $4.5 \mathrm{~kg}$ is applied over the sample and, a piston of $50 \mathrm{~mm}$ of diameter penetrates into the soil, obtaining a curve loaddisplacement to compute the final value of CBR [39]. In the confinement situation, the soil is maintained inside the mold during the penetration stage, whereas in the unconfined conditions, the specimen is tested outside the mold, trying to reproduce a real critical low-confinement situation: the soil under the piston only had a column of soil around it of thickness almost equal to the diameter of the piston. As a result, for the same amount of cement, the comparison of these two "modified" CBR values determines the effect of the lateral confinement of the mold on the bearing capacity in the improved sand.

230

\section{Results and discussion}

\subsection{Moisture content - dry density relationship}

Figure 7 presents the relationship between moisture content and dry density for the three percentages of cement investigated, also including the untreated material for sake of comparison. For each case, two curves are included (dotted lines) corresponding to each series developed. In all cases, the compaction curves are repetitive and consistent, displaying slight differences between each couple of curves in every case. The average result estimated is also provided (continuous line), highlighting the pair of values: optimum water content-maximum dry density, for every case.

For untreated sand (without cement), the optimum water content is $13.7 \%$ and the corresponding maximum dry density equal to $1630 \mathrm{~kg} / \mathrm{m}^{3}$, which is in agreement with the properties of aeolian sand reported by other researchers in the literature. It can be clearly observed that as 
the cement content increases, the maximum dry density also does so, while the optimum water content decreases, which is particularly relevant in arid areas due to the lack of water.

On the other hand, in all cases the maximum dry density reached after the treatment is higher than in the case of untreated sand, while this trend does not occur for the optimum water content respect to the untreated sand.

In Figure 8 and Figure 9, the relationships between the values of maximum dry density and optimum moisture content respect to the cement content (\%), are respectively drawn. In both graphs, the experimental results and a trend line of them are included. As it can be observed, for both parameters, there is an almost perfect linear trend line with respect to \% cement, yielding a correlation coefficient equal to $R^{2}=0.9946$, for maximum dry density, and $R^{2}=0.9994$, for optimum moisture content. So, it can be affirmed that there is a linear behavior between dosage of cement and compaction results. The obtained correlations, for Jeddah aeolian sand, are:

\subsection{Bearing capacity ratio: confinement and unconfinement conditions}

The "modified" CBR results obtained for both confined and unconfined conditions are shown in of tests, for each percentage of cement, including the untreated material, are given. In particular, it was no possible to carry out the unconfinement-test for untreated material because the specimen could not even support the overload before the penetration stage due to the lack of confinement and total absence of cohesion. Nevertheless, the results of the modified CBR for untreated sand under confined conditions are provided as a reference in Figure 11 (dotted line).

As expected, from the obtained results, it can be concluded that the higher the cement content, the higher the "modified" CBR values under both confined and unconfined conditions. Specially, the improvement reached under the unconfinement condition is very relevant, since thanks to the 
admixture of cement, even for the lowest content of the additive, the sand develops a minimum bearing capacity, enough to perform the unconfinement-test.

On the other hand, unlike the common soils, the CBR obtained are almost independent of the energy of compaction (number of blows by layer), particularly for the confinement-test, and even slightly decreases for the unconfinement-test. This behavior can be observed both for the untreated sand and for every cement content. So it can be concluded that, for this type of soil, in spite of the cement additive, higher compaction energy in the compaction process does not imply a significant improvement in the bearing capacity.

In Figure 12, it has been plotted the curves load-displacement obtained from the modified-CBR developed, both for confinement condition (left graphs) respect to the unconfinement tests (right graphs), for aeolian sand alone and also for every cement content. The curves included in every graph correspond to the three different compaction energy degrees adopted in the tests. For all energies of compaction in each dosage, all the results are very similar, what it is not usual in soils, and because of that, the CBR is almost independent of the compaction energy for a cementstabilization of this sand, as it has already been observed in Figure 10 and Figure 11 . In contrast, the behavior under confined conditions respect to unconfined is absolutely different. Comparing both graphs, it can be observed that the curve load-displacement shows a progressive increment until reach a maximum, followed by a slight decrement for confinement-test. In contrast, for unconfined-test, the load-displacement curve increases sharply until reaches a clear peak, and after that, the curve decreases quickly to maintain approximately constant in a low value, which corresponds to the failure of the specimen. Both performances are very similar for all the cement contents analyzed.

In Figure 10 and Figure 11, it can be observed a clear translation of the curves to higher values of "modified" CBR for higher cement contents, this tendency is plotted in Figure 13. Since the bearing capacity is almost constant and independent of energy compaction, the average value between the three ratios of energy has been adopted for each case (Table 4). The mean value of "modified" CBR depends linearly of the cement content with a correlation factor $\mathrm{R}^{2}=0.9993$ and $\mathrm{R}^{2}=0.9697$ for the confinement and unconfinement conditions, respectively. Although the improvement of the bearing capacity with the cement admixture, in terms of the average modified $\mathrm{CBR}$, is more relevant in the case of confined than for unconfined conditions (higher slope in the 
linear trend line), the latest is very significant as well, because it allows the utilization of this materials under low confinement conditions in earth structures, as for example in some parts of embankments. The obtained correlations, for Jeddah aeolian sand, are:

Confined: $M m C B R=37.567 \mathrm{Cem}(\%)-17.189$

Unconfined: $M m C B R=1.85 \operatorname{Cem}(\%)-2.1111$

Finally, to measure the degree of improvement reached with this treatment, two simple but illustrative indices, related to bearing capacity, are defined: $U B C_{x}$, for Unconfined Bearing Conditions and $\mathrm{x} \%$ of cement, and $\mathrm{CBC}_{\mathrm{x}}$, for Confined Bearing Conditions and $\mathrm{x} \%$ of cement. These new indices try to measure the degree of improvement achieved in the bearing capacity with this stabilization under low or high confinement conditions respect to the original situation (untreatedconfined sand), which are defined as follows:

$$
U B C_{x i}=\frac{M m C B R U_{x}}{M m C B R C_{O}}
$$

$$
C B C_{x i}=\frac{M m C B R C_{x}}{M m C B R C_{0}}
$$

where $M m C B R U_{x}$ is the mean "modified" CBR under unconfined condition for $x \%$ of cement, $\mathrm{MmCBRC}_{\mathrm{x}}$ is the mean "modified" CBR for confined condition, while $\mathrm{MmCBRC}_{0}$ is the average value for confined sample of untreated sand. These are dimensionless numbers and note that, if $\mathrm{UBC}_{\mathrm{x}}$ reaches 1 or more, the treated- unconfined material would achieve, at least, the same bearing capacity as the untreated-confined sand.

The results of $\mathrm{UBC}_{\mathrm{x}}$ and $\mathrm{CBC}$, for Jeddah aeolian sand improved with cement are presented in Table 4, and the evolution of both indices is compared in Figure 14, where linear trend lines can also be obtained. It can be concluded that, for equal percentage of cement $(x \%)$ the improvement is more important in the confined conditions (higher values of $\mathrm{CBC}_{\mathrm{x}}$ ) due to, obviously, the advantageous influence of confinement degree, as can be observed comparing the slopes of both adjustments (2.89 for confined index respect to 0.13 for unconfined index). For the most adverse situation, i.e. in those parts of geotechnical structure with low o null confinement contributions, values of cement content close to $6 \%$ are required to achieve an $\mathrm{UBC}_{\mathrm{x}}$ next to 1 , since for lower percentage of cement, $\mathrm{UBC}_{\mathrm{x}}$ is markedly lower than this value. Therefore, as the bearing capacity 
of the untreated-confined material is acceptable for the construction of embankments, cement contents lower than $6 \%$ of cement are not recommended on the lateral sides of the embankments, where the confinement is very limited. In that way, bearing capacity in the laterals of embankments (treated unconfined sand) is similar to the bearing capacity in the internal zone of embankments when it can be executed without any stabilization treatment (untreated confined sand), obtaining a similar bearing capacity in the whole embankment.

\section{Conclusions}

In this paper, the experimental research carried out on ground improvement of Aeolian sand from Jeddah (Saudi Arabia), by stabilization with cement (additive), is presented. The main aim of this research is to evaluate the effect of different percentages of cement on the compaction and bearing capacity properties of this special type of sand, particularly under low confinement conditions, which is one of its particular drawbacks. The main derived conclusions are:

- The main characteristics of Jeddah aeolian sand are in agreement with most of the dune materials properties reported in the literature, particularly in terms of similar particle size distribution, mineralogy, texture, and compaction features. observed respect to the influence of cement content, for both compaction and bearing capacity. The higher the percentage of cement, the higher the maximum dry density and the higher bearing capacity ("modified" CBR), whereas the lower optimum moisture content, which could be an advantage in arid regions. By means of the correlation established from the experimental data, several useful expressions have been proposed along the research.

- Unlike of common soils, for this aeolian sand under cement-stabilization, bearing capacity is almost independent of energy of compaction.

- The influence of the degree of confinement has been analyzed carefully along this research, defining even a modification in the laboratory CBR procedure to try to investigate this problematic condition by means of two critical situations: confined and unconfined experiments. The improvement of the treatment has been reviewed depending on this external condition. Unfortunately, it has not been possible to compare with the results driven by other authors, 
since in most of the cases, strength parameters are reported instead of bearing capacity (CBR), and less, with unconfined bearing capacity.

- $\quad$ Although the bearing capacity values rise with the increment of the percentage of cement, this improvement was more relevant in the case of confined samples, but very important as well in the unconfined tests, allowing to use of this material, after treated, in low confinement placements, which would be absolutely impossible without the cement-stabilization.

- The load-displacement curve of this material during CBR test strongly depends on the confinement degree of the specimen but is almost independent of the $\%$ of cement, at least in its shape although not in magnitude.

- $\quad$ The UBC $x$ and $\mathrm{CBC}_{\mathrm{x}}$ indices presented, can be adopted as a simple but practical and efficient manner to evaluate the improvement of the bearing capacity after the stabilization of aeolian sands with an additive, in particular cement, for both high and low confinement conditions. Moreover, both indices can be also extrapolated to evaluate the improvement due to other additives.

Alternative additives could also be employed to stabilize this type of sand and improve their engineering characteristics. Currently, the authors of this investigation are working in that sense.

\section{Acknowledgements}

The authors of this paper want to thank Prof. Anselmo Acosta for his help and support on the characterization of the Jeddah sand, and also to the firm Santano (Cáceres) for supplying the additive employed in this research. This investigation would not have been possible without the help received from Ms. Begona Perez-Moraga and Dr. Edrees El-Helaly on the very difficult administrative process for the acquisition of the sand from Jeddah (Saudi Arabia). The financial support received from the Spanish Ministry of Science and Innovation (BIA2012-31678) during the early stages of this research is also appreciated.

\section{References}

[1] Pye, K. \& Tsoar, H., (2009). Aeolian sand and sand dunes. Berlin: Springer-Verlag.

[2] Beadnell, H.J.L., (1909). An Egyptian oasis. London: Murray.

386

[3] Beadnell, H.J.L., (1910). The sand dunes of the Libyan desert. The Geographical Journal, 35 (2), 379-395. 
[4] Bagnold, R.A., (1941). The physics of blown sand and desert dune. London: Methuen and Co.

[5] Milton, D.I., (1967). Geology of the Arabian Peninsula: Kuwait. U.S. Geological Survey Professional Paper 560-F.

[6] Al-Sayari, S.S. and Zötl, J.G., (1978). Quaternary Period in Saudi Arabia, Vienna: SpringerVerlag.

[7] Ahlbrandt, T.S., (1979). Textural parameters of aeolian deposits. In: A study of global sand seas (Ed. by McKee, E. D.). U. S. Geological Survey Professional Paper 1052, 21-52.

[8] Fryberger, S.G., (1979). Dune forms and wind regime. In: A study of global sand seas (Ed. by McKee, E. D.). U. S. Geological Survey Professional Paper 1052, 137-169.

[9] McKee, E. D., (1979). An introduction to the study of global sand seas. In: A study of global sand seas (Ed. by McKee, E. D.). U. S. Geological Survey Professional Paper 1052, 1-19.

400

[11] Abu-Zeid, M. M., Baghdady, A. R. and El-Etr, H. A., (2001). Textural attributes, mineralogy and 401 provenance of sand dune fields in the greater Al Ain area, United Arab Emirates. Journal of Arid Environments, 48 (4), 475-499. doi:10.1006/jare.2000.0776

[12] Bakliwal, P.C. and Wadhawan, S.K., (2003). Geological evolution of Thar Desert in India Issues and prospects. Proceedings of the Indian National Science Academy, 69A (2), 151-165.

[13] Howari, F.M., Baghdady, A., Goodell, P.C., (2007). Mineralogical and geomorphological characterization of sand dunes in the eastern part of United Arab Emirates using orbital remote sensing integrated with field investigations. Geomorphology 83, 67-81. doi:10.1016/j.geomorph.2006.06.015

[14] Khan, I. H., (1982). Soil studies for highway construction in arid zones. Engineering Geology, $19,47-62$.

[15]Al-Sanad, H.A. and Bindra, S.P., (1984). Soil mechanics for road engineers in Arabian Peninsula. Kuwait University, Kuwait.

[16] Al-Sanad, H. A., Ismael, N. F. and Nayfeh, A. J., (1993). Geotechnical properties of dune sands in Kuwait. Engineering Geology, 34, 45-52. 
[17] Yuan, Y., Wang, X. and Zhou, X., (2008). Experimental research on compaction characteristics of aeolian sand. Frontiers of Architecture and Civil Engineering in China, 2 (4), 359-365. doi:10.1007/s11709-008-0053-3

[18] Al-Ansary, M., Pöppelreiter, M. C., Al-Jabry, A. and lyengar, S. R., (2012). Geological and physiochemical characterization of construction sands in Qatar. International Journal of Sustainable Built Environment, 1, 64-84. doi:10.1016/j.jisbe.2012.07.001

[19] Padmakumar, G. P., Srinivas, K., Uday, K. V., lyer, K. R., Pathak, P., Keshava, S. M. and Singh, D. N., (2012). Characterization of aeolian sands from Indian desert. Engineering Geology, 139140, 38-49. doi:10.1016/j.enggeo.2012.04.005

[20] Al-Taie, A. J., Al-Shakarchi, Y. J. and Mohammed, A. A., (2013). Investigation of geotechnical specifications of sand dune: a case study around Baiji in Iraq. International Journal of Advanced Research, 1 (6), 208-215.

[21]Zhang, G., Song, J., Yang, J. and Xiyuan, L., (2006). Performance of mortar and concrete made with a fine aggregrate of desert sand. Building and Environment, 41, 1478-1481. doi:10.1016/j.buildenv.2005.05.033

[22] Al-Harthy, A. S., Halim, M. A., Taha, R. and Al-Jabri, K. S., (2007). The properties of concrete made with fine dune sand. Construction and Building Materials, 21, 1803-1808. doi: 10.1016/j.conbuildmat.2006.05.053

[23] Abu Seif, E. S., (2011). Assessing the engineering properties of concrete made with fine dune sands: an experimental study. Arabian Journal of Geosciences, 1-7. doi:10.1007/s12517-0110376-6

[24] Abu Seif, E. S., (2013). Performance of cement mortar made with fine aggregates of dune sand, Kharga Oasis, Western Desert, Egypt: an experimental study. Jordan Journal of Civil Engineering, 7 (3), 270-284.

[25] Luo, F. J., He, L., Pan, Z., Duan, W. H., Zhao, X. L. and Collins, F., (2013). Effect of very fine particles on workability and strength of concrete made with dune sand. Construction and Building Materials, 47, 131-137. doi: 10.1016/j.conbuildmat.2013.05.005

[26] Elipe, M.G.M. and Lopez-Querol, S. (2014). Aeolian sands: characterization, options of improvement and posible employment in construction - The State-of-the-art. Construction and Building Materials, 73, 728-739. doi: 10.1016/j.conbuildmat.2014.10.008 
[27] Al-Khanbashi, A. and El-Gamal, M., (2003). Modification of sandy soil using water-borne polymer. Journal of Applied Polymer Science, 88, 2484-2491.

[28] Aiban, S. A., (1994). A study of sand stabilization in eastern Saudi Arabia. Engineering Geology, 38, 65-79.

[29] Al-Aghbari, M. Y. and Dutta, R. K., (2005). Suitability of desert sand cement mixes for base courses in highway pavements. Electronic Journal of Geotechnical Environment, 10 (D).

[30] Moosavi, K. and Kalantari, B., (2011). Improving load bearing capacity of wind-blown sand using ordinary Portland cement. Electronic Journal of Geotechnical Environment, 16(Q), 12671274.

[31] AlKarni, A. and ElKholy, S. M., (2012). Improving geotechnical properties of dune sands through cement stabilization. Journal of Engineering and Computer Sciences, 5 (1), 1-19.

[32] Ghrieb, A., Mitiche-Kettab, R. and Bali, A., (2013). Stabilization and utilization of dune sand in road engineering. Arabian Journal for Science and Engineering. doi:10.1007/s13369-013$0721-z$

[33]UNE-EN 197-1 (2011). Cemento. Parte 1: Composición, especificaciones y criterios de conformidad de los cementos communes (in Spanish). (Equivalent to: BS EN 197-1 (2011). Cement. Composition, specifications and conformity criteria for common cements.)

[34] UNE 103101 (1995). Análisis granulométrico de suelos por tamizado (in Spanish). (Equivalent to: ASTM D422-63 (2007) Standard Test Method for Particle-Size Analysis of Soils

[35] ASTM D2487 - 11. Standard Practice for Classification of Soils for Engineering Purposes (Unified Soil Classification System).

[36] AASHTO M 145 - 82 (1991). Standard Specification for Classification of Soils and SoilAggregate Mixtures for Highway Construction Purposes.

[37] Pinard, M.I. and Motswagole, K.J. (2010). The use of Kgalagadi sands in road construction. Gaborone: Botswana Roads Department (Guideline No 11).

[38]UNE 103501 (1994). Geotecnia. Ensayo de compactación. Proctor modificado (in Spanish). (Equivalent to: ASTM D1557-12. Standard Test Methods for Laboratory Compaction Characteristics of Soil Using Modified Effort.) 
[39] UNE 103502 (1995). Método de ensayo para determinar en laboratorio el índice C.B.R. de un suelo (in Spanish). (Equivalent to: ASTM D1883-16. Standard Test Method for California Bearing Ratio (CBR) of Laboratory-Compacted Soils.)

[40] UNE-EN 12390-2 (2009). Ensayos de hormigón endurecido. Parte 2: Fabricación y curado de probetas para ensayos de Resistencia (in Spanish). (Equivalent to: BS EN 12390-2 (2009). Testing hardened concrete. Making and curing specimens for strength tests.) 


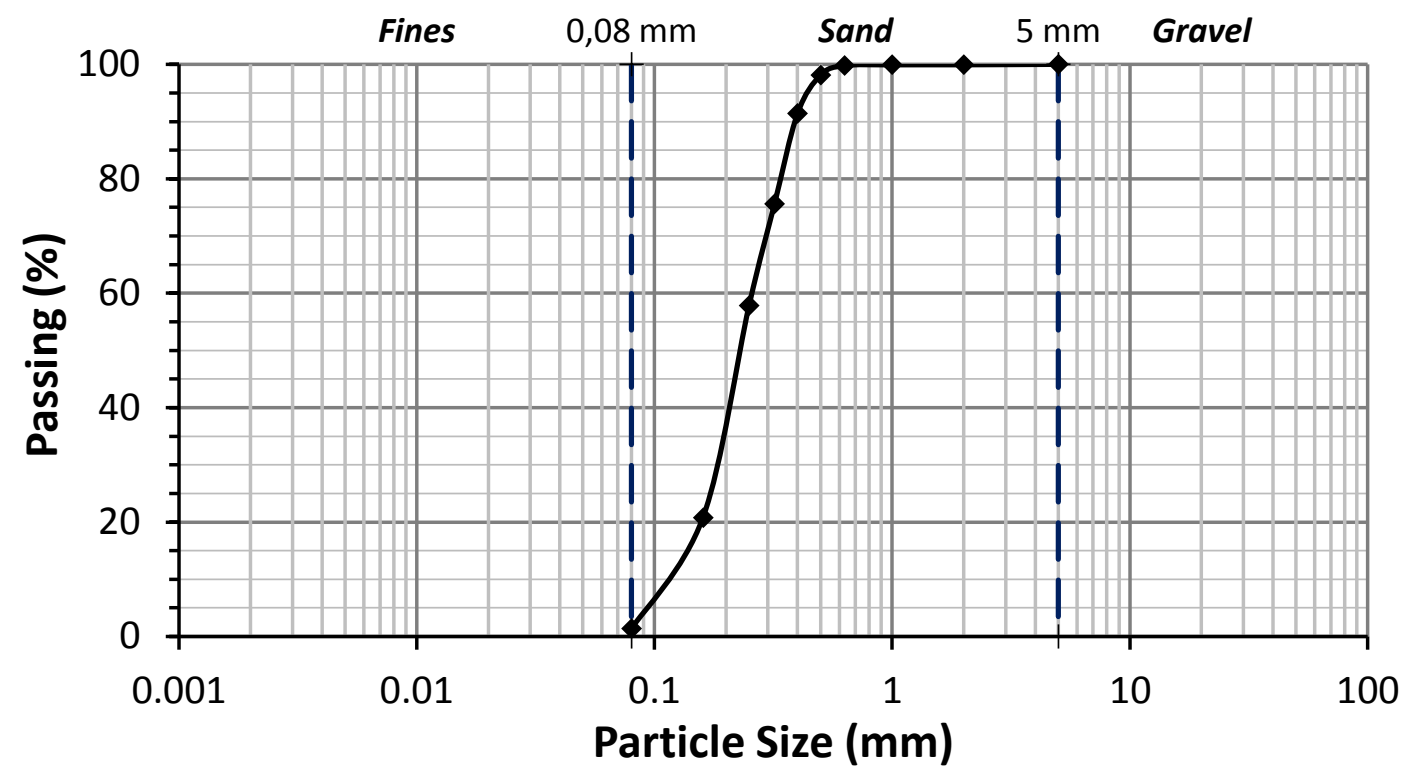

480

Figure 1. Particle size distribution by sieving of Jeddah aeolian sand 


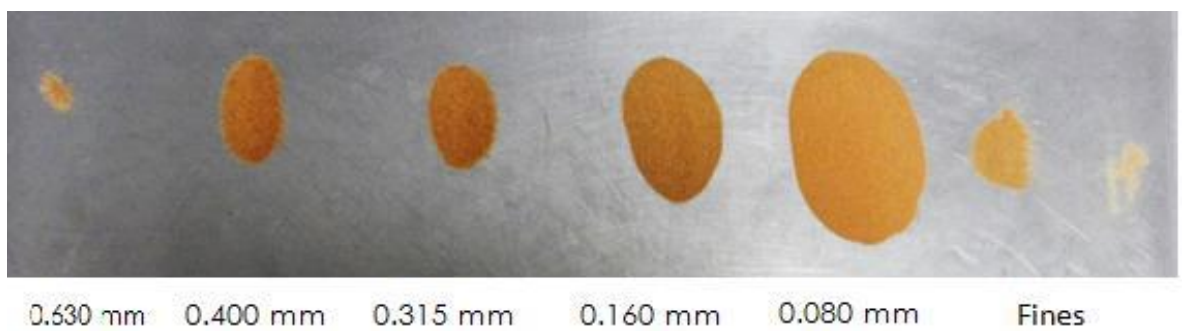

483 Figure 2. Pictures of the different size fractions of Jeddah aeolian sand

484 


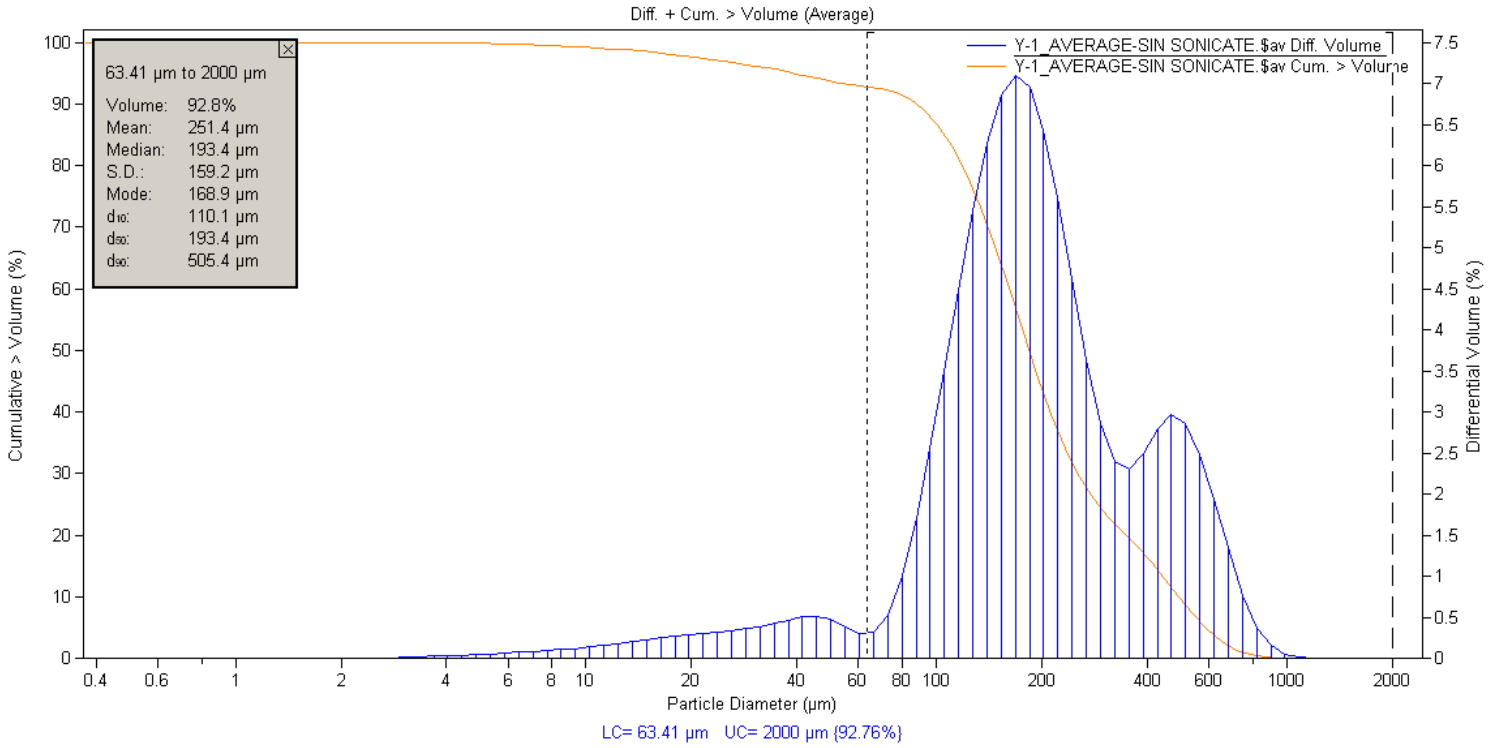

486

Figure 3. Laser-ray diffraction analysis of Jeddah aeolian sand 


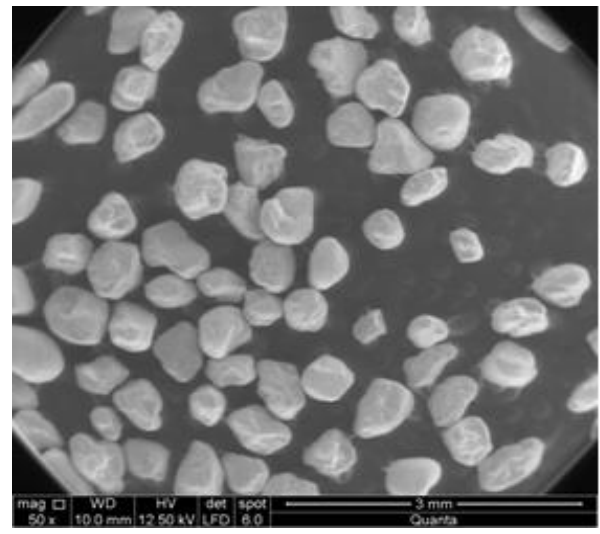

a)

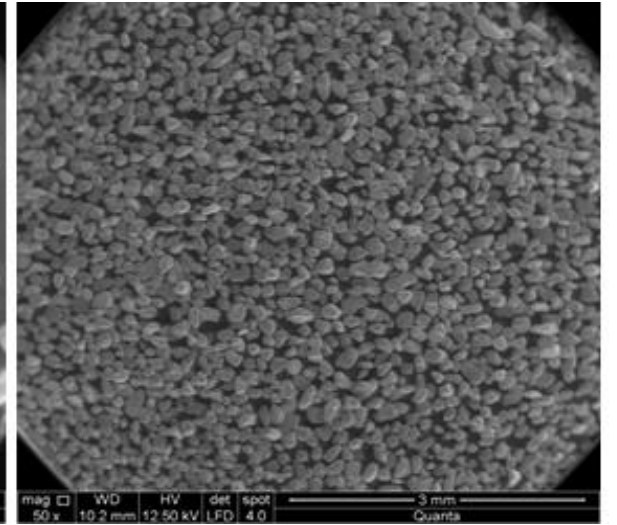

b)

490 Figure 4. Electronic microscope: 50x micrographs for Jeddah aeolian sand. a) Y-1G: fraction with

491 particle size greater than $0.160 \mathrm{~mm}$; b) Y-1F: fraction with the finest particle size, smaller than 0.160

492 $\mathrm{mm}$

493 


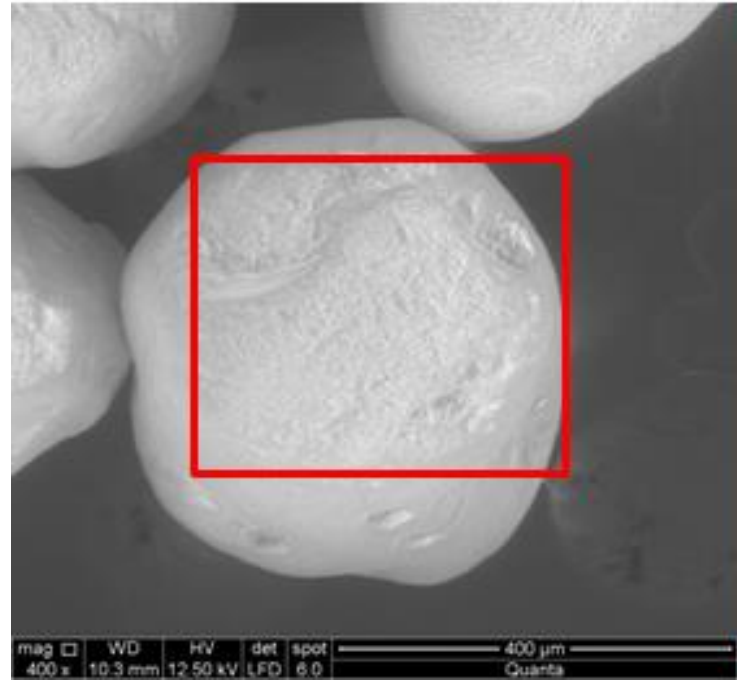

a)

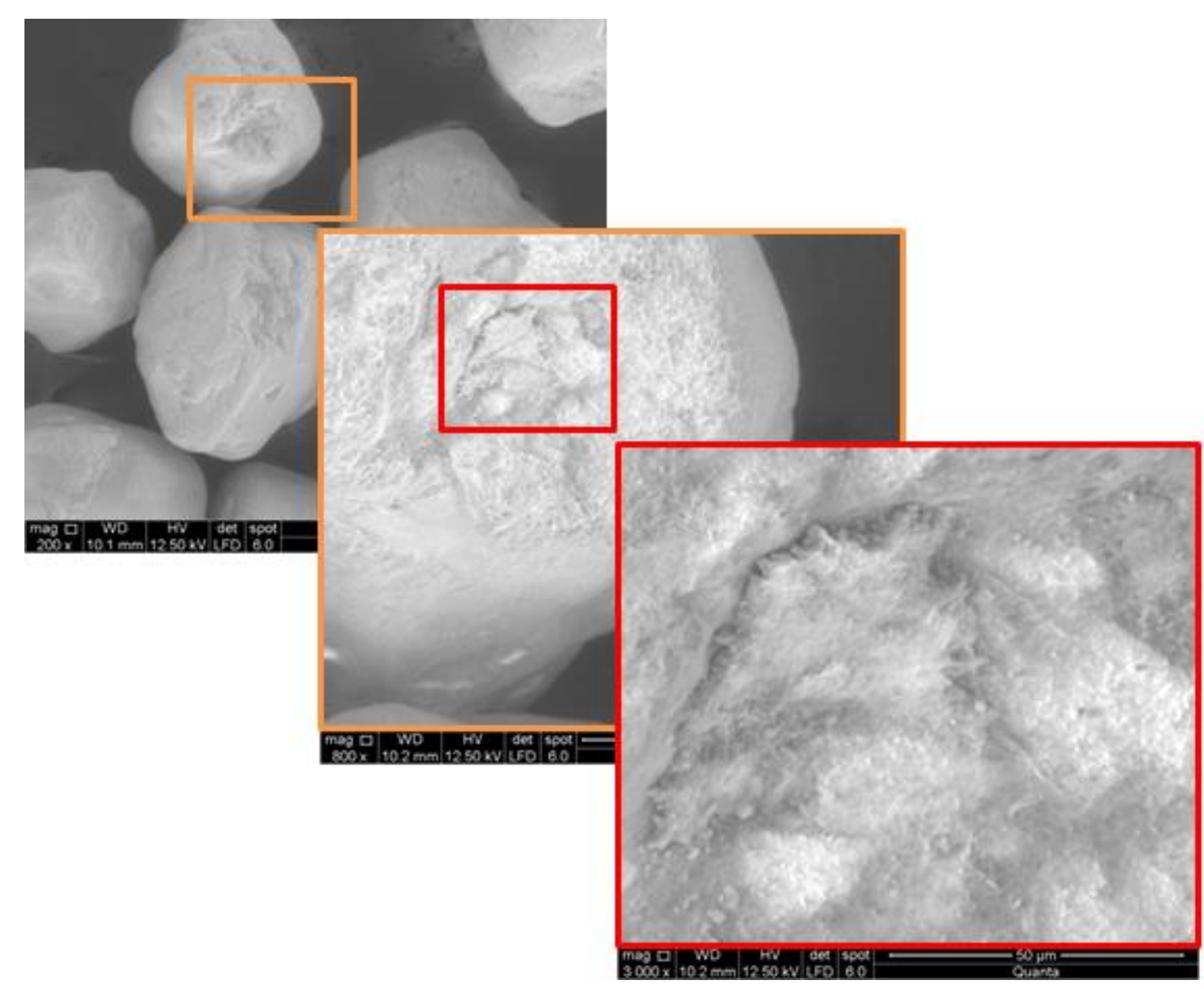

c)

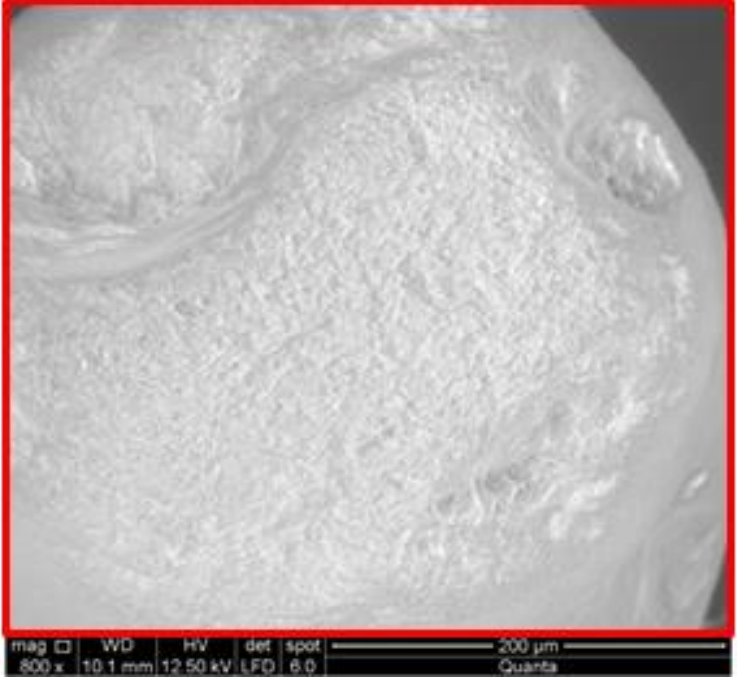

b)

494 Figure 5. Electronic microscope: Micrographs for $Y-1 G$ fraction. a) $\times 400$; b) $\times 800$; c) $\times 200$, $x 800$ and 


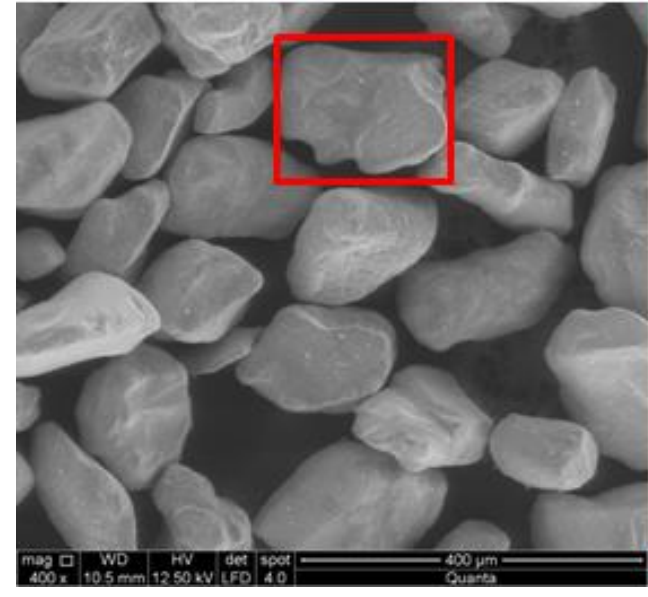

a)

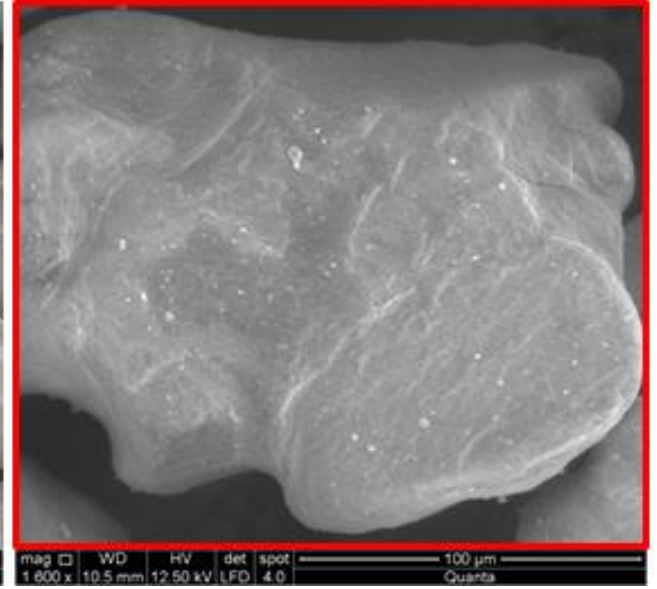

b)

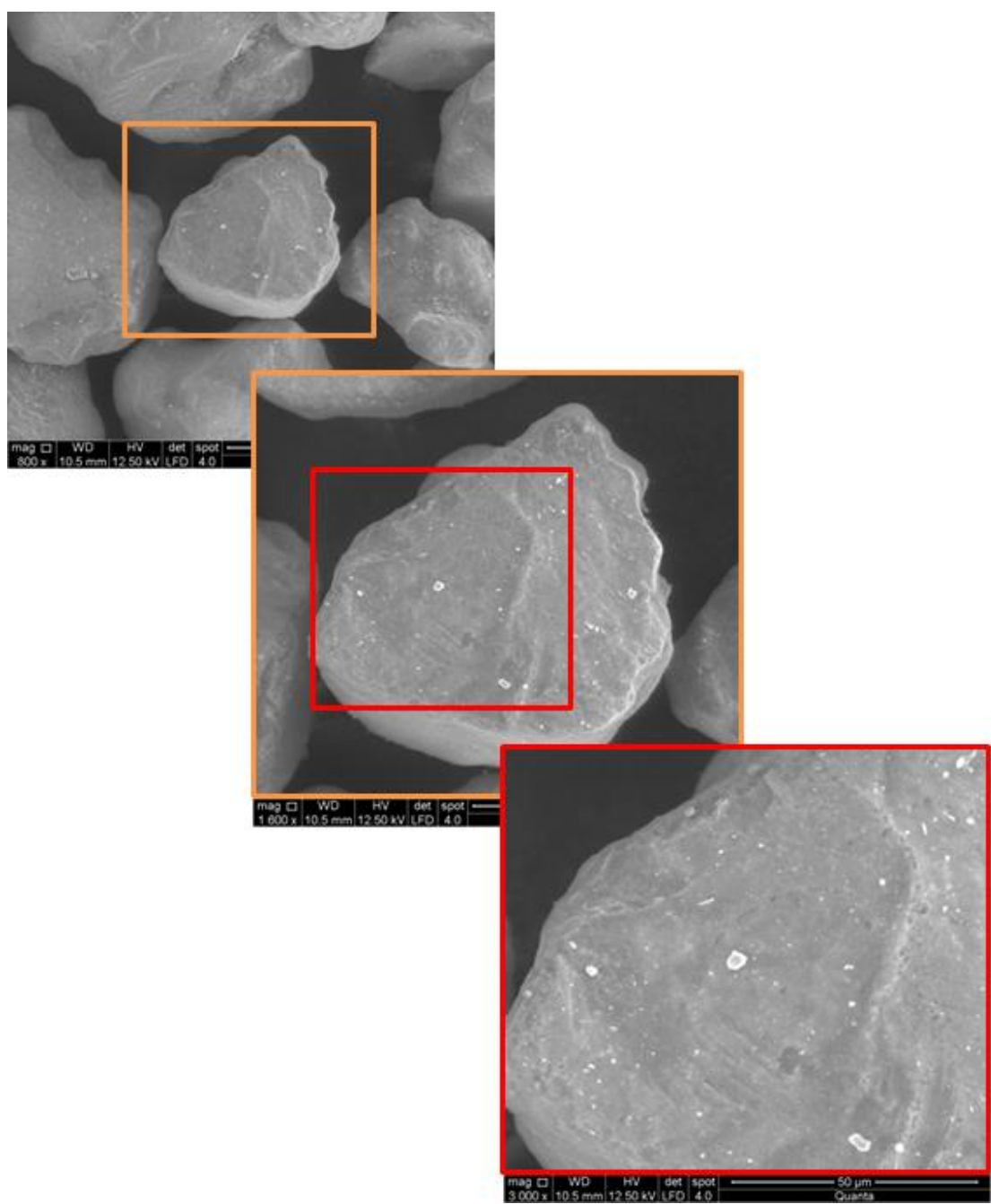

c)

496 Figure 6. Electronic microscope: Micrographs for $\mathrm{Y}-1 \mathrm{~F}$ fraction. a) $\mathrm{x} 400$; b) $\mathrm{x} 1600$; c) $\mathrm{x} 800$, $x 1600$ 497 and $\times 3000$ 


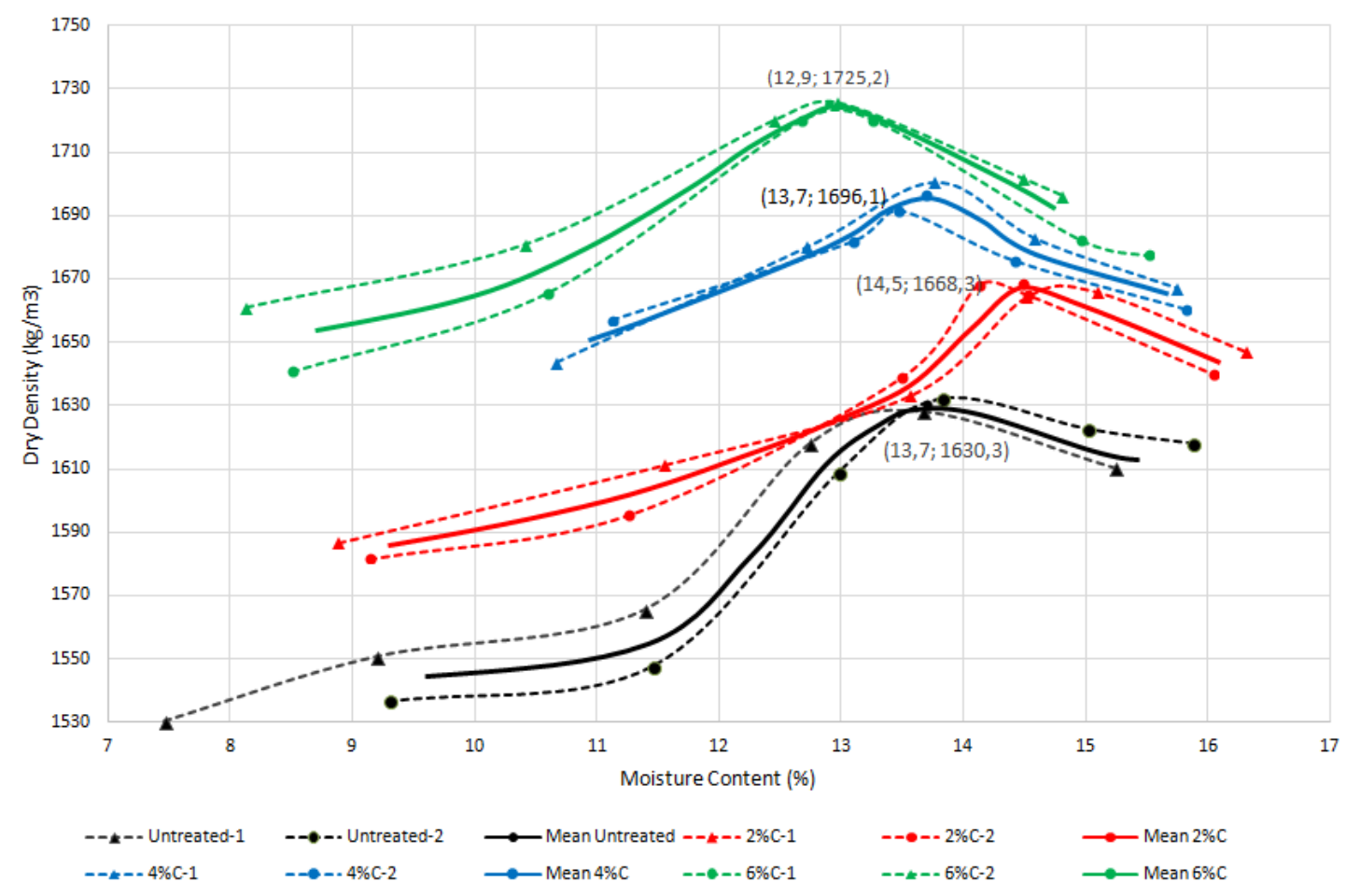

500 Figure 7. Dry density - moisture content relationships for Jeddah Aeolian Sand: Untreated sand and

501 different dosages of cement-stabilization. Compaction curves through Modified Proctor test. (Notation:

$502 \mathrm{X} \% \mathrm{C}-\mathrm{Y}, \mathrm{X}$ is the percentage of cement considered and $\mathrm{Y}$ denotes the number of series testing for 503 each cement content; "mean" denotes the average results of series 1 and 2 in each case). 


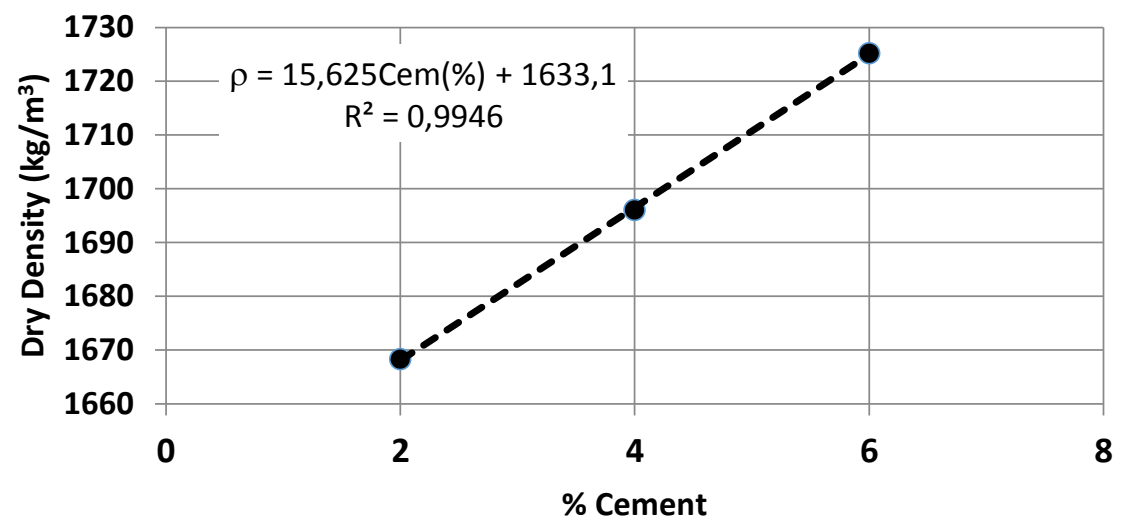

- Mean Maximum Dry Density _ - - Linear (Mean Maximum Dry Density)

506 Figure 8. Maximum dry density for each percentage of cement after compaction process.

507 (Experimental results in circles and linear adjustment in dotted line) 


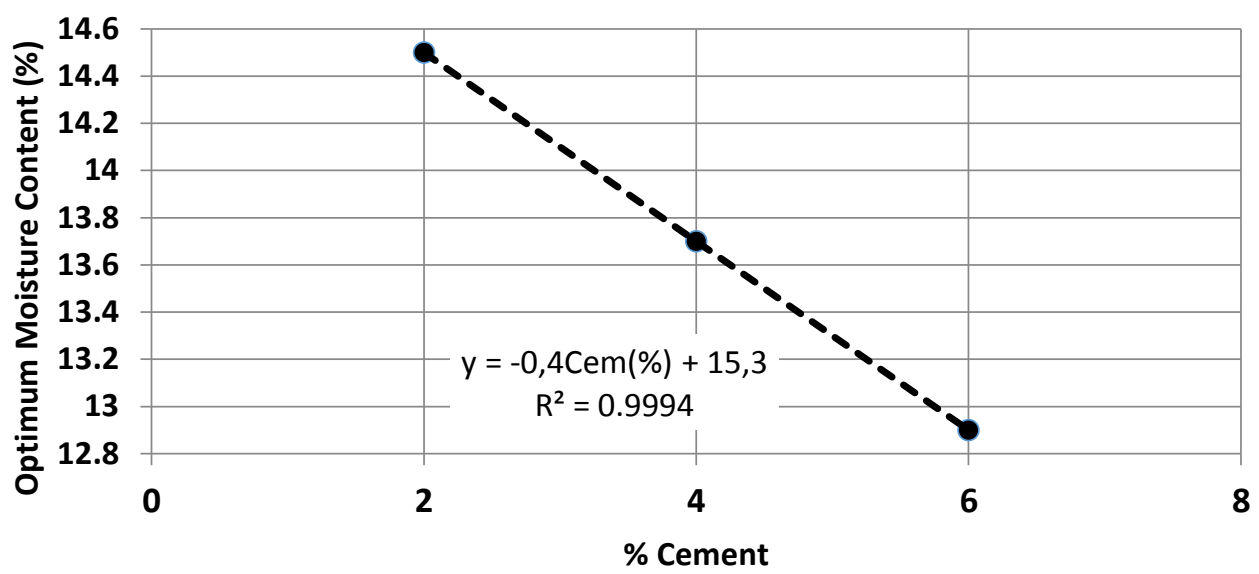

- Mean Optimum Moisture Content - - - Linear (Mean Optimum Moisture Content)

510 Figure 9. Optimum water content for each percentage of cement after compaction process.

511 (Experimental results in circles and linear adjustment in dotted line) 
Confinement - Condition

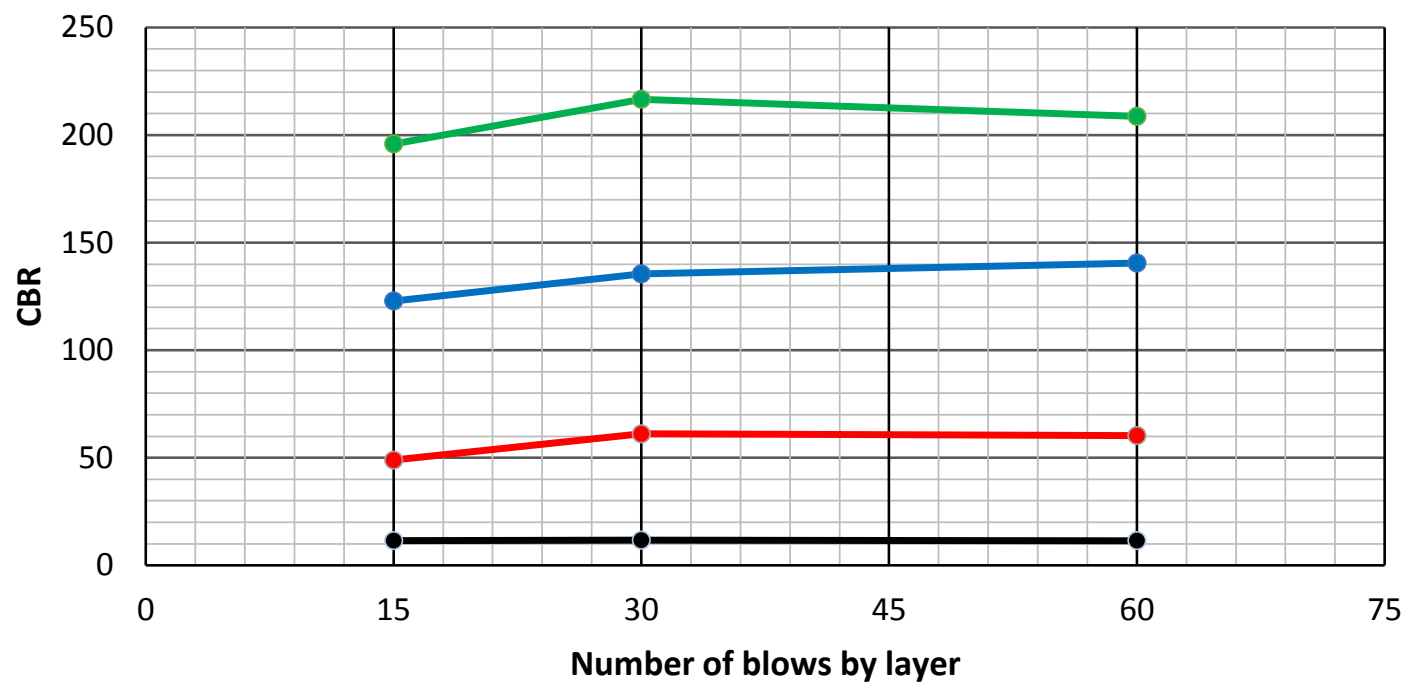

515

-@-Untreated Sand $-\bullet$ Mean 2\% Cement $\longrightarrow$ Mean 4\% Cement $\longrightarrow$-Mean 6\% Cement

516 Figure 10. Confined specimens: values of bearing capacity ("modified" CBR) respect to different

517 levels of energy (blows by layer), for every dosages of cement $(2 \%, 4 \%$, and $6 \%)$ and untreated

518 material. $(15,30$ and 60 blows by layer represent $25 \%, 50 \%$ and $100 \%$ of the corresponding energy

519 in the reference compaction test)

520 


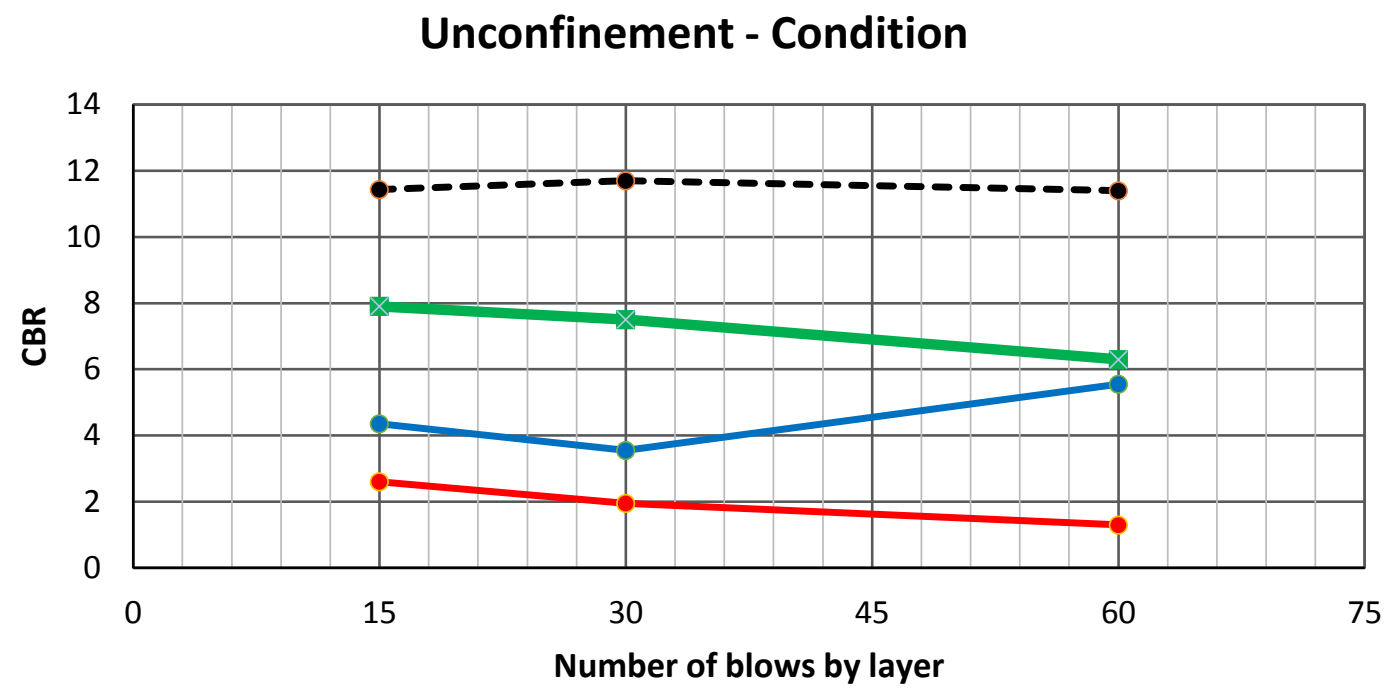

- - - Untreated Sand (Confinement Condition) - $\longrightarrow$ Mean 2\% Cement

523 Figure 11. Unconfined specimens: values of bearing capacity ("modified" CBR) respect to different

524 levels of energy (blows by layer) for every dosages of cement $(2 \%, 4 \%$, and $6 \%)$. The results

525 obtained for untreated sand under confinement condition have been maintained for comparison. (15,

52630 and 60 blows by layer represent $25 \%, 50 \%$ and $100 \%$ of the corresponding energy in the

527 reference compaction test) 

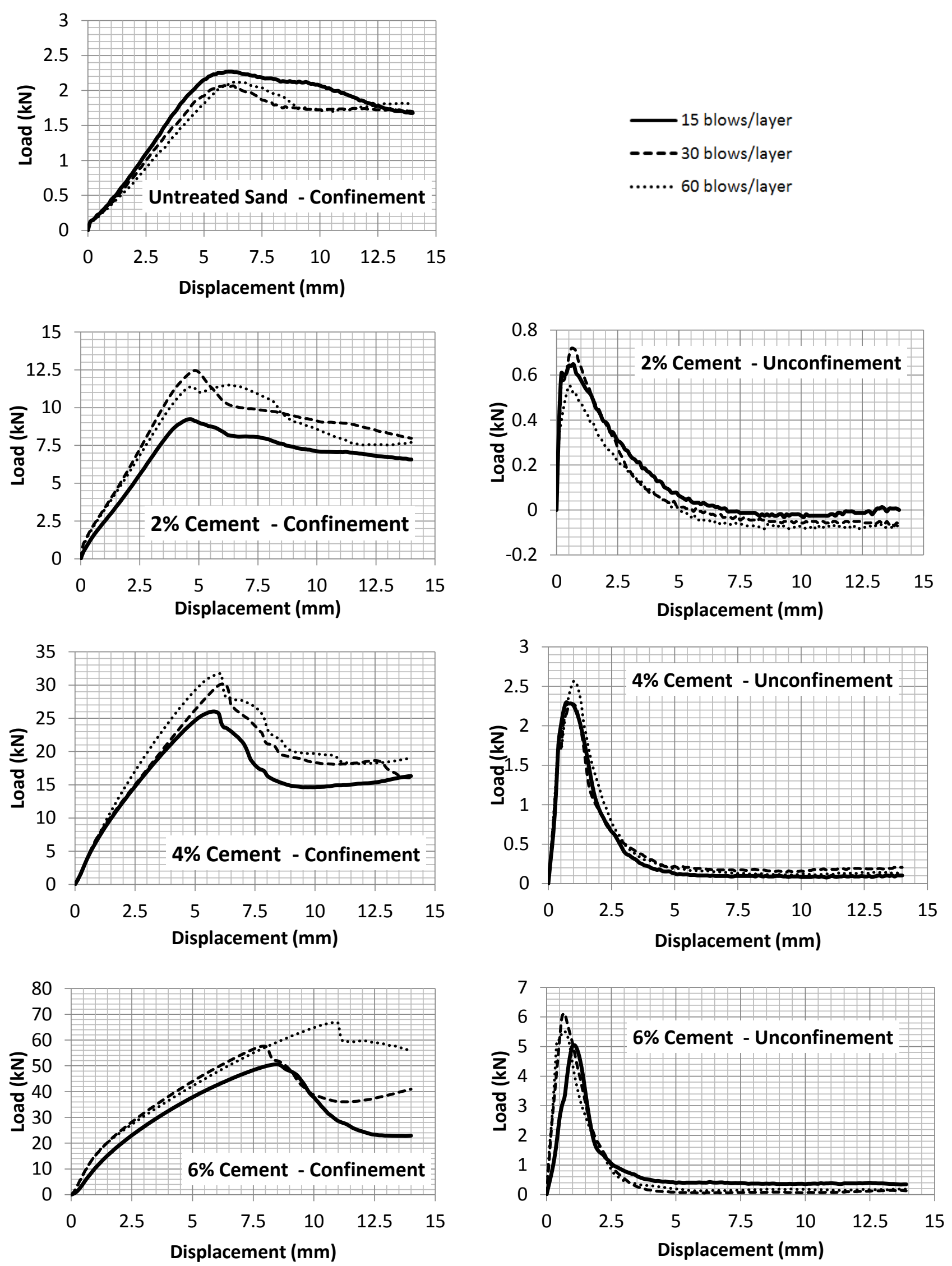

Figure 12. Curves load-displacement corresponding to the penetration stage of the specimens (CBR

530 test), for different compaction energy degree (blows by layer), under confined and unconfined

531 conditions and for untreated material and three dosages of cement $(2 \%, 4 \%$, and $6 \%)$ 


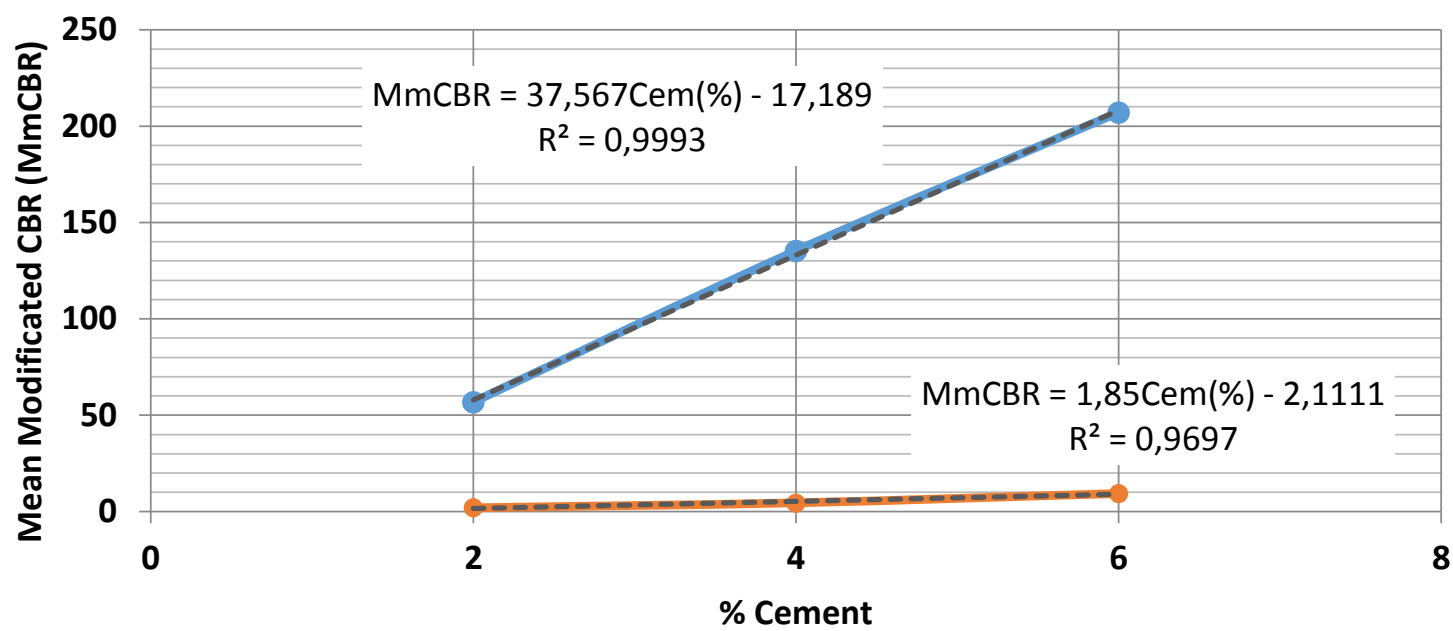

533

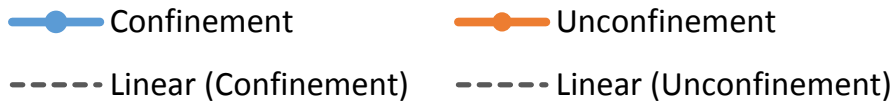

534 Figure 13. Mean "modified" CBR results related to the percentage of cement for confined and

535 unconfined condition. Linear tendencies are also included 


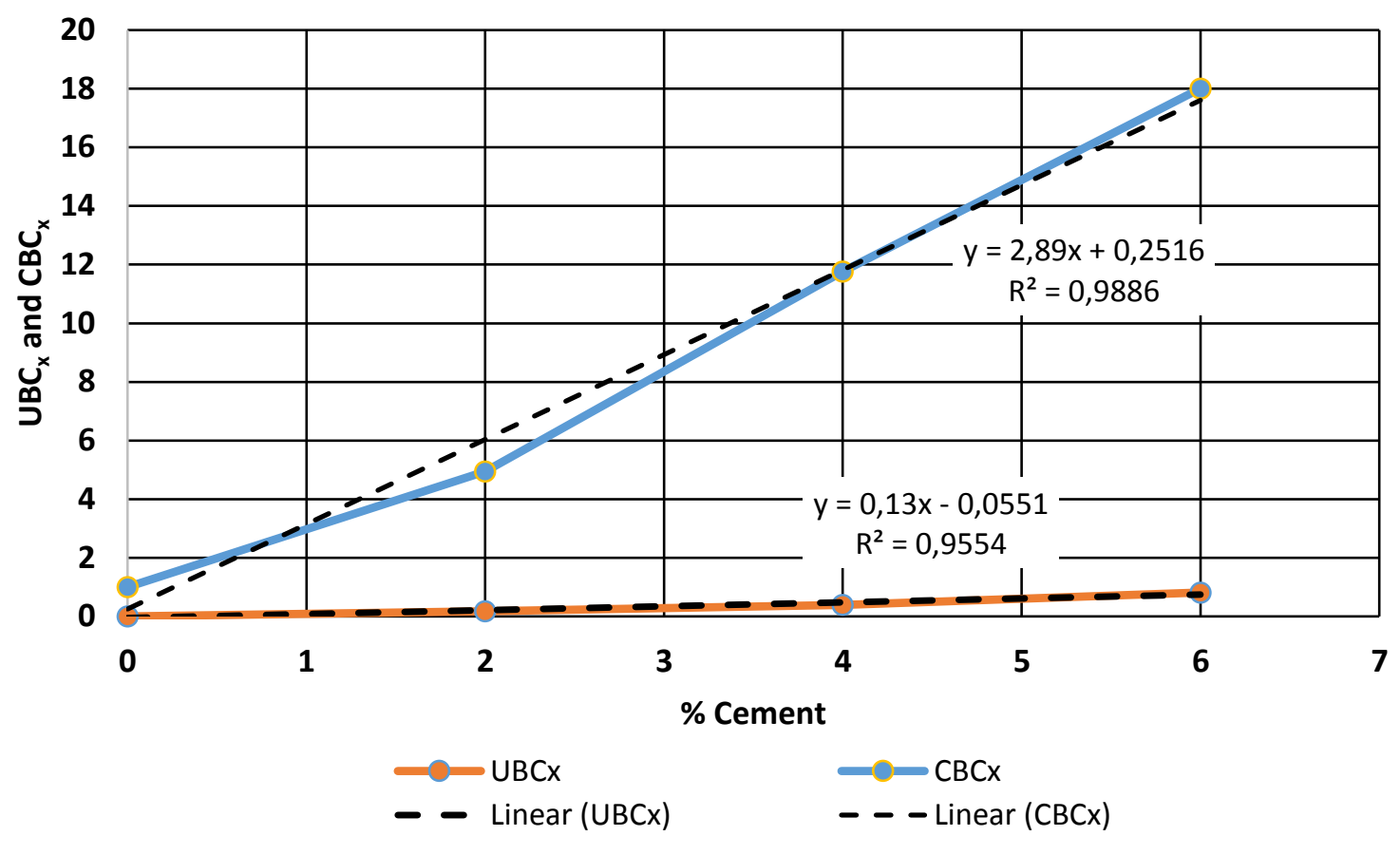

538 Figure 14. Evolution of the indices $\mathrm{UBC}_{\mathrm{x}}$ (unconfined condition) and $\mathrm{CBC}_{\mathrm{x}}$ (confined condition) for 539 the different dosages of cement. Linear tendencies are also included 
542 Table 1. Summary of the physical properties of Jeddah aeolian sand

\begin{tabular}{|l|l|}
\hline Soil property & Result \\
\hline Specific gravity (Gs) & 2.67 \\
\hline Initial moisture content (\%) & 0.27 \\
\hline$D_{10}(\mathrm{~mm})$ & 0.109 \\
\hline $\mathrm{D}_{30}(\mathrm{~mm})$ & 0.179 \\
\hline $\mathrm{D}_{60}(\mathrm{~mm})$ & 0.258 \\
\hline $\mathrm{C}_{u}$ & 2.37 \\
\hline $\mathrm{C}_{\mathrm{c}}$ & 1.14 \\
\hline Carbonate (qualitative analysis with acid test) & YES \\
\hline Color & Reddish \\
\hline Classification soil (USCS) & SP - Poorly graded sand \\
\hline Classification soil (AASTHO) & A3 \\
\hline
\end{tabular}

543

544 Note: $D_{10}=$ grain diameter at $10 \%$ passing; $D_{30}=$ grain diameter at $30 \%$ passing; $D_{60}=$ grain diameter at

$54560 \%$ passing; $\mathrm{C}_{\mathrm{u}}=$ coefficient of uniformity; Cc: coefficient of curvature 
547 Table 2. Mineralogical composition of Jeddah aeolian sand

\begin{tabular}{|l|l|l|l|}
\hline Composition & Quartz & Calcite & Feldspar \\
\hline Content & $73.8 \%$ & $22.9 \%$ & $3.3 \%$ \\
\hline
\end{tabular}

548

549 
550 Table 3. Dimensions of tested specimen and characteristics of compaction procedure

\begin{tabular}{|l|l|}
\hline \multicolumn{2}{|c|}{ Tested specimen } \\
\hline Diameter $(\mathrm{mm})$ & 152.5 \\
\hline Height $(\mathrm{mm})$ & 76.2 \\
\hline Volume $\left(\mathrm{cm}^{3}\right)$ & 1392 \\
\hline Hammer Diameter $(\mathrm{mm})$ & 50 \\
\hline Hammer Mass $(\mathrm{kg})$ & 4.535 \\
\hline Hammer Height $(\mathrm{cm})$ & 457 \\
\hline Number of Layers & 3 \\
\hline Blows by layer & 60 \\
\hline Compaction Energy $\left(\mathrm{J} / \mathrm{cm}^{3}\right)$ & 2.632 \\
\hline
\end{tabular}

551

552 
553 Table 4. Mean "modified" CBR results and the indices $\mathrm{CBC}_{\mathrm{x}}$ and $\mathrm{UBC}_{\mathrm{x}}$ for different percentage of 554 cement

\begin{tabular}{|c|c|c|c|c|}
\hline $\begin{array}{c}\text { Cement } \\
\text { content (\%) }\end{array}$ & $\begin{array}{c}\text { MmCBR - } \\
\text { Confined Tests }\end{array}$ & $\begin{array}{c}\text { UnCBR - } \\
\text { Unconfined Tests }\end{array}$ & $\begin{array}{c}\text { CBC } \\
\text { (Confined Bearing } \\
\text { Capacity index) }\end{array}$ & $\begin{array}{c}\text { (Confined Bearing } \\
\text { Capacity index) }\end{array}$ \\
\hline Without \\
Cement & 11.50 & $\begin{array}{c}\text { Not possible } \\
(0.00)\end{array}$ & 0.00 & 1.00 \\
\hline 2 & 56.83 & 1.97 & 0.17 & 11.77 \\
\hline 4 & 135.30 & 4.53 & 0.39 & 18.01 \\
\hline 6 & 207.10 & 9.37 & 0.81 & \\
\hline
\end{tabular}

555 